\title{
Analysis combustion efficiency in a fluidized-bed combustor with a modified perforated plate for air distribution
}

\author{
Erdiwansyah Erdiwansyah ${ }^{1,5}$, Mahidin Mahidin², Husni Husin ${ }^{2}$, Nasaruddin Nasaruddin $^{3}$, \\ Muhtadin Muhtadin ${ }^{4}$, M. Faisal ${ }^{4}$, Asri Gani $^{2}$, Usman $^{4}$, Rizalman Mamat ${ }^{6}$ \\ ${ }^{1}$ Doctoral Program, School of Engineering, Post Graduate Program, Universitas Syiah Kuala, Banda \\ Aceh 23111, Indonesia \\ ${ }^{2}$ Department of Chemical Engineering, Universitas Syiah Kuala, Banda Aceh 23111, Indonesia \\ ${ }^{3}$ Department of Electrical and Computer Engineering, Universitas Syiah Kuala, Banda Aceh 23111, \\ Indonesia \\ ${ }^{4}$ Department of Mechanical Engineering, Universitas Abulyatama Aceh, Aceh Besar 23372, Indonesia \\ ${ }^{5}$ Faculty of Engineering, Universitas Serambi Mekkah, Banda Aceh 23245, Indonesia \\ ${ }^{6}$ Faculty of Mechanical Engineering, Universiti Malaysia Pahang, 26600, Malaysia \\ Corresponding Author: erdi.wansyah@yahoo.co.id and mahidin@unsyiah.ac.id
}

\begin{abstract}
Combustion efficiency is one of the most important parameters, especially in the FBC combustion chamber. Investigations into the efficiency of combustion in FBC fuels using solid biomass waste fuels in recent years are increasingly in demand by researchers around the world. Specifically, this study aims to calculate the combustion efficiency in the FBC combustion chamber. Combustion efficiency is calculated based on combustion results from modification of hollow plates in the FBC combustion chamber. The modified hollow plate aims to control combustion so that the fuel incorporated can burn out and not saturate. The combustion experiments were tested using palm oil biomass solid waste fuels such as PKS, OPM, and EFB. The results of the measurements showed that the maximum combustion temperature for $\mathrm{MCC}$ fuel reached $863^{\circ} \mathrm{C}$ for $\mathrm{M} 1$ and $887^{\circ} \mathrm{C}$ on $\mathrm{M} 2$. The maximum combustion temperature measurements for M1 and M2 from OPM fuel testing reached $898^{\circ} \mathrm{C}$ and $858^{\circ} \mathrm{C}$, respectively, while the maximum combustion temperature for EFB fuel was $667^{\circ} \mathrm{C}$ andM2 $847^{\circ} \mathrm{C}$, respectively. The rate of combustion efficiency with the modification of the hole plate in the FBC combustion chamber reached 96.2\%. Thermal efficiency in FBC combustion chamber for OPM 72.62\%, MCC 70.03\%, and EFB 52.43\%. The highest heat transfer rates for OPM fuel reached $7792.36 \mathrm{w} / \mathrm{m}$, MCC $7167.38 \mathrm{w} / \mathrm{m}$, and EFB $5127.83 \mathrm{w} / \mathrm{m}$. Thus, modification of the holed plate in the FBC chamber showed better performance of the plate without modification.
\end{abstract}

Keywords: Fluidized-Bed Combustor, Perforated Plate, Heat transfer, Thermal efficiency, Combustion efficiency. 


\section{Introduction}

Investigations into the efficiency of combustion in FBC fuels using solid biomass waste fuels in recent years are increasingly in demand by researchers around the world. This is due to the existence of highly promising solid biomass waste that can be converted into energy. Solid biomass waste is one of the renewable energy sources that can be converted to replace fossil energy that has been decreasing in recent years. The availability of renewable energy is currently abundant in Southeast Asia [1-3]. Abundant renewable energy sources today, one of which is a solid waste of palm oil biomass [4-6]. Meanwhile, an analysis of the availability of energy from palm oil biomass waste has also been conducted [7]. Where the results of the analysis with simulations conducted showed that biomass solid waste can produce energy of 106.15 MW from the results of a mixture of several types of biomass. While one type of biomass alone can produce energy of 61.05 MW. Thus, renewable energy sources from palm oil biomass solid waste are suitable for reducing dependence on fossil fuels, especially in remote areas/islands.

Combustion efficiency is one of the most important parameters especially in the combustion chamber such as Fluidized-Bed Combustor (FBC). Combustion efficiency, $\chi$, can generally be defined as in Equation (1). Equation (1) shows the definition for combustion efficiency i.e., the ratio of chemical heat release rate (HRR), $\mathrm{Q}_{\mathrm{CH}}$, to heat of perfect combustion

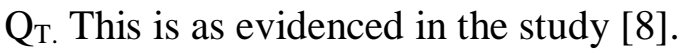

$$
\mathrm{X}=\frac{Q_{C H}}{Q_{T}}
$$

An investigation into the efficiency of combustion in the combustion chamber with a case study in a 1:20 scale tunnel has recently been conducted [9]. Where the results obtained show that the length of the tunnel can affect the efficiency of combustion. The average value of propane fire recorded reaches $89 \%$ and for heptane, fire is lower which is $80 \%$. The chemical HRR value decreased from normal fire, but the heptane combustion efficiency rate reached 94\%. Research to predict combustion efficiency in methane and propane fires has also been conducted [10]. Where overall combustion efficiency was found to be close to one unit through various oxidizing dilutions, but at the beginning of testing, there was a sudden decrease. In different studies conducted with combustion experiments using porous and non-porous alumina base fuel in the FBC, fuel chamber has been investigated [11]. Where the results obtained that polypropylene can be used effectively to fuel on both materials FBC. Experiments conducted showed a combustion efficiency rate of $99.9 \%$ at $750^{\circ} \mathrm{C}$. Detailed process development to evaluate the heat potential of biomass combustion results in CFB combustion 
chambers with Aspen Plus simulator and FORTRAN special subroutines have also been analyzed [12]. An investigation into the efficiency of combustion in FBC fuel using sawdust, rice husks, and cane pulp has been discussed [13]. The experiments tested in the study aimed to investigate temperature, $\mathrm{CO}, \mathrm{NO}$, and $\mathrm{CO}_{2}$ concentrations along with the height of the combustion chamber as well as exhaust gases (chimneys). Operating conditions and fuel properties can affect overload and air.

Research with the use of perforated plate quatrefoil (QPP) designed for the optimization of heat exchangers has recently been studied [14]. The main purpose of the study was to study the degree of influence on hole height and QPP plate distance on thermal-hydraulic performance. The results showed that the coefficient of heat transfer and pressure drop on the shell side of the heat exchanger increased with a decrease in hole height and plate distance from QPP. However, the level of heat transferred on the side of the shell becomes reduced. Experiments to investigate hydrodynamic loads with two-dimensional perforated plates have been studied [15]. The test results between the two hollow plates with gaps of 0.14 and 0.29 overall showed an excellent association. Modification of hollow plates in the FBC fuel chamber with the use of biomass solid waste fuel is still very little found in the literature. Investigation of combustion efficiency in the FBC fuel chamber, especially with palm oil biomass fuel is also very rarely found in publications. Therefore, research to analyze the efficiency of combustion by making various modifications in the combustion chamber is very important. This is because the use of biomass solid waste as a very abundant source of renewable energy can be used as an alternative fuel to reduce dependence on fossil energy.

The investigation through experiments conducted in the study specifically aimed to calculate the efficiency of combustion in the FBC combustion chamber. Efficient combustion is calculated based on a modification of the hole plate contained in the FBC combustion chamber. The modified hollow plate aims to control combustion so that the fuel incorporated can burn out and not saturate. The combustion experiments were tested using palm oil biomass solid waste fuels such as palm kernel shell (PKS), oil palm midrib (OPM), and empty fruit bunches (EFB).

\section{Material and Experimental Setup}

This research was conducted to analyze the level of combustion efficiency through modification of perforated plates as well as different fuels. This test was conducted twice for 
each of the different fuels. For the type of fuel and experiment setup designed in the research as described in the stages below.

\subsection{Fuel Material}

The fuel materials used in the study were a solid waste of palm oil biomass such as palm kernel shell (PKS), oil palm midrib (OPM), and empty fruit bunches (EFB). Each type of fuel used in this experiment weighed $2.5 \mathrm{~kg}$ as shown in Fig. 1.

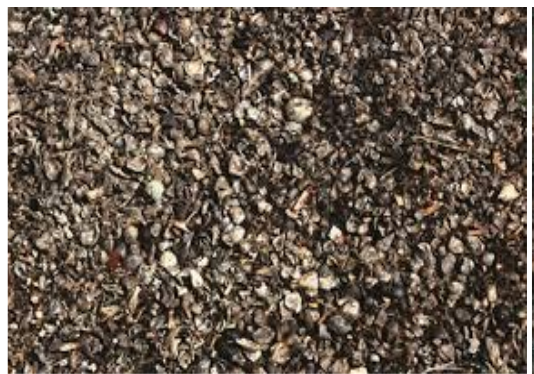

A. PKS

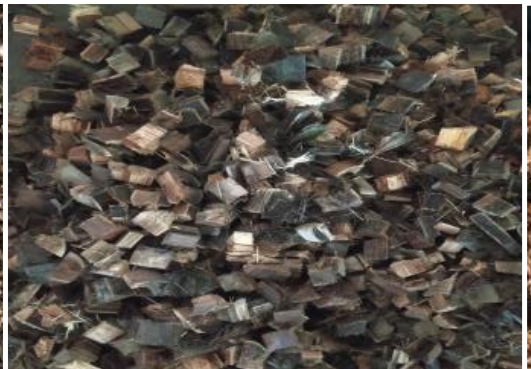

B. OPM

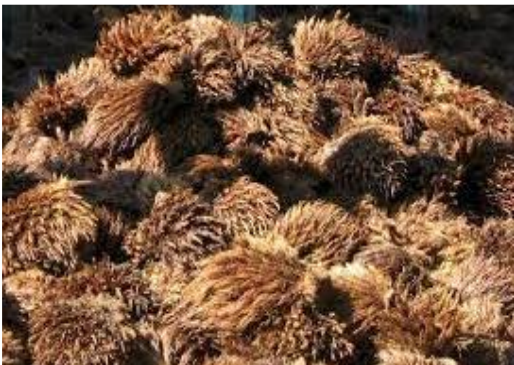

C. EFB

Fig. 1. Types of Palm Oil Biomass Fuel

\subsection{Experimental Setup}

The testing tools used in this experiment include combustion chambers (FBC) and blowers. The designed combustion chamber has an inner circle diameter of $30 \mathrm{~cm}$ with a height of $47 \mathrm{~cm}$. Blowers used for wind suppliers into the combustion chamber have a pressure of $14.7 \mathrm{kPa}$ shown in Fig. 2. The temperature measurements and combustion efficiency performed in this experiment were placed at five different points. Measurement is done using Digital Thermometer HotTemp HT-306 brand. The measurement tool is denoted M1 (Flame Temperature), M2 (Fire End Temperature), M3 (Lower Freeboard Temperature), M4 (Upper Freeboard Temperature), and M5 (Outer Combustor Wall Temperature). 

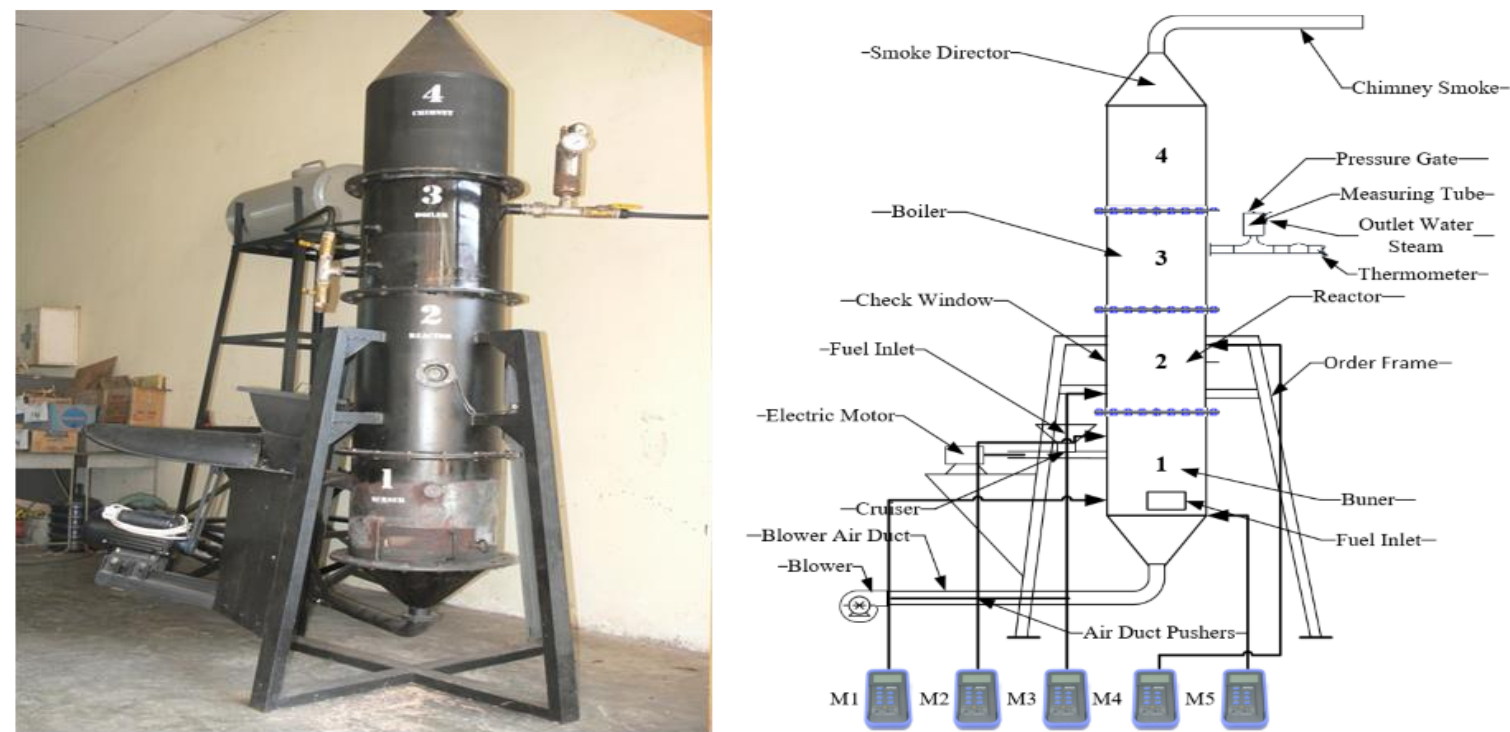

Fig. 2. Eksperimentan Setup

The modification of perforated plates made in this study aims to analyze the level of breeding efficiency using different fuels. Modifications made include making a hole as many as 32 by adding a spoonful of four pieces and the main hole placed in the middle of the plate. This is made to provide a windway that enters the combustion chamber so that the fuel inside is not saturated. Plate modifications were made in this test as shown in Fig. 3.
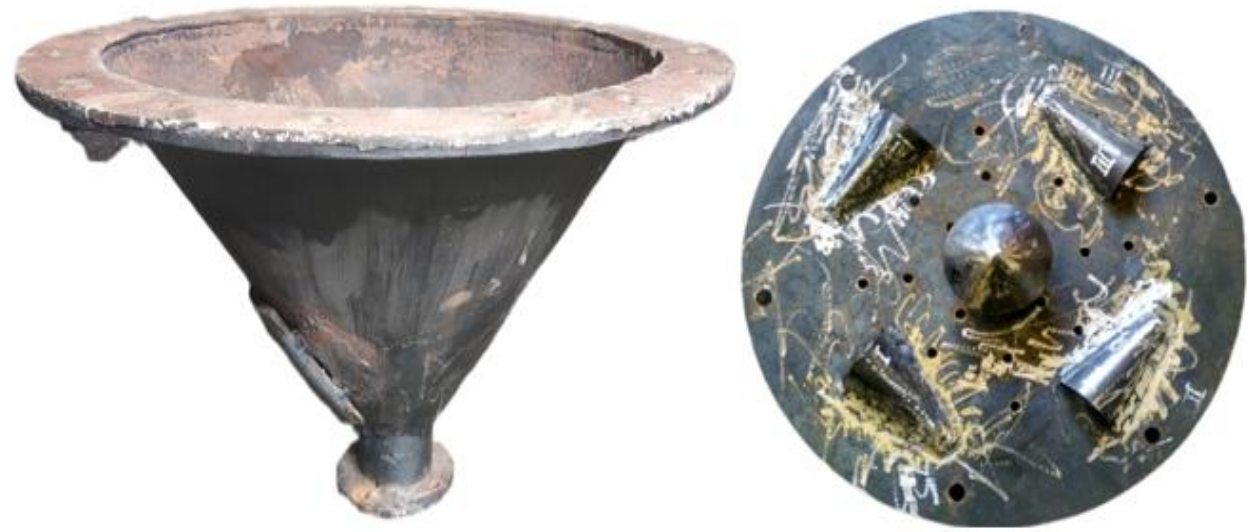

Fig. 3. Modification of Hollow Plate with Four Spoons

Furthermore, the steaming of combustion temperature in this study uses Digital Thermometer HT-306 as shown in Fig. 3. While the specifications of the Digital Thermometer HT-306 are presented in Table 1. 

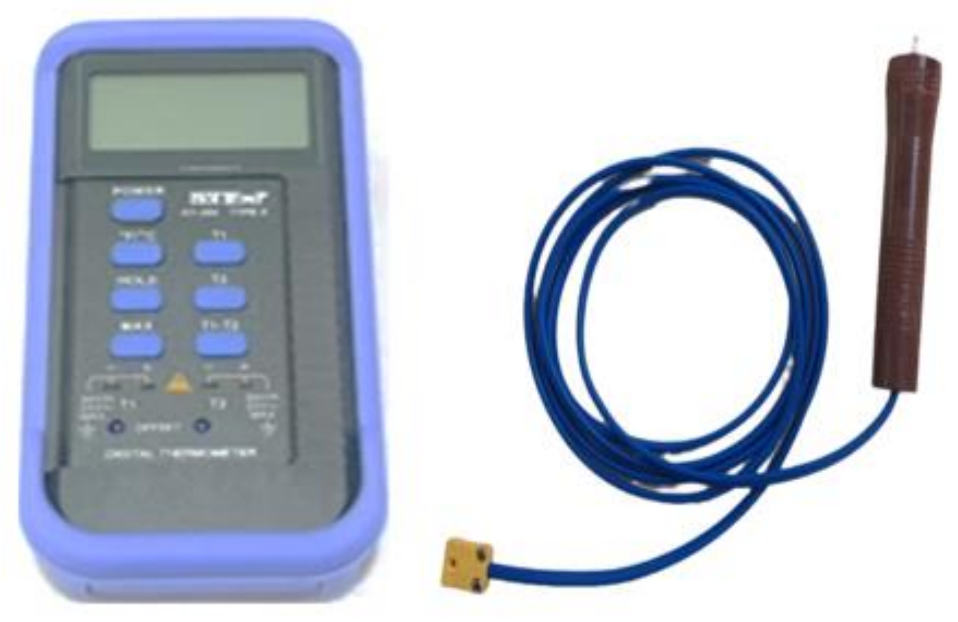

Fig. 3. Digital Thermometer merk HotTemp HT-306

Table 1 Specification Thermometer Digital HT-306

\begin{tabular}{ll}
\hline \multicolumn{1}{c}{ Component } & \multicolumn{1}{c}{ Measurement } \\
\hline Model HT-306 & Dual Channel Input \\
Input Sensor & Thermocouple Type "K" \\
Resolution & $\mathrm{HT}-306: 1^{\circ} \mathrm{C} / 1^{\circ} \mathrm{F}$ \\
Response Time & 15 Seconds \\
Wide Measuring Range & $-50^{\circ} \mathrm{C} \sim+1300^{\circ} \mathrm{C}\left(-58^{\circ} \mathrm{F} \sim+1999^{\circ} \mathrm{F}\right)$ \\
Power Supply & Baterai $6 \mathrm{~F} 229 \mathrm{~V}$ \\
\hline
\end{tabular}

\section{Result and Discussion}

\subsection{Temperature Influence of Walled Plate Modification}

The experiments conducted in this study were tested at five different points with their respective details (M1; M2; M3 M4; and M5. Specifically, the discussion presented in this study is the thermal temperature and efficiency of the different fuel test results. Experiments in this study analyze the level of combustion efficiency in the combustion chamber by modifying the perforated plate with four steering directors plus the main steering wheel located in the middle of the plate that has been designed. The results of the combustion temperature analysis measured on M1 as shown in Fig. 4.a. At the time of the initial combustion to the seventh second indicates that the temperature of the $\mathrm{OPF}$ fuel reaches $370^{\circ} \mathrm{C}$ which is recorded at the fifth second. While PKS and EFB fuels showed lower yields. However, at the time of burning time of 8-16 seconds, the PKS burn increased to $863^{\circ} \mathrm{C}$ and at $20-30$ seconds the trend 
decreased. While the resulting maximum temperature OPM fuel is recorded at 21 seconds which reaches $898^{\circ} \mathrm{C}$. While the maximum temperature that fuels the $\mathrm{EFB}$ is $667^{\circ} \mathrm{C}$ is recorded at 18 seconds. The low temperature resulting from OPM combustion due to higher moisture content is raised by $\mathrm{PKS}$ and EFB.

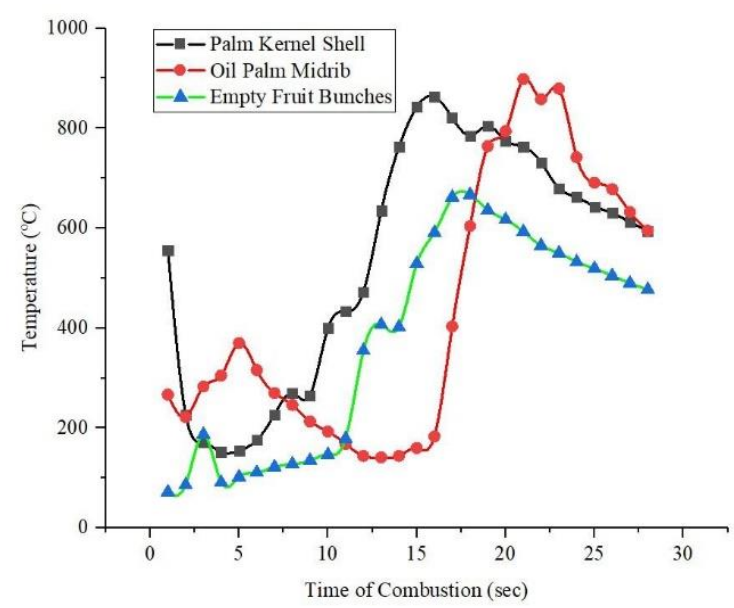

a. Combustion temperature at M1

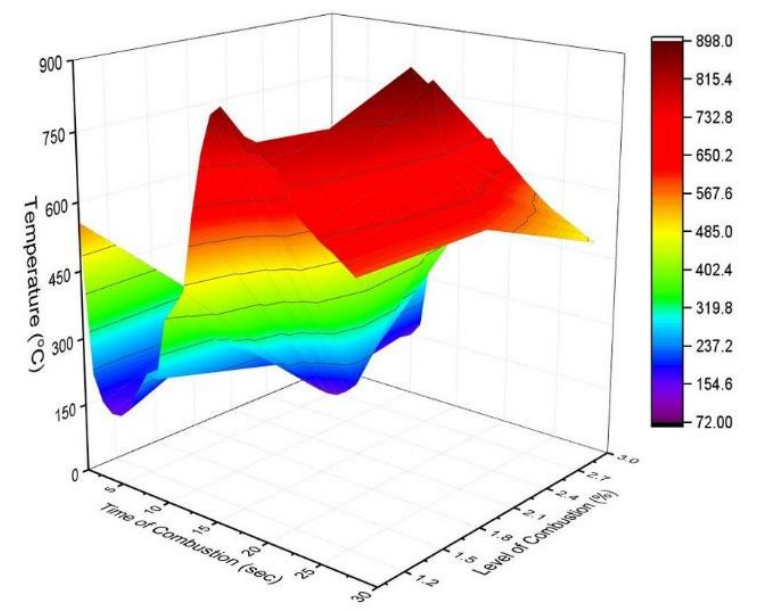

b. Temperature with 3D display

Fig. 4. M1 Combustion Temperature Levels of Three Different Fuels

The combustion temperature of OPM fuel began to increase at seconds $12-18$ and so on continued to decrease until the end of testing. The desperation temperature produced in this study is mainly for OPM fuel slightly lower than the results of the study [16]. However, the amount of fuel in this experiment was less so the resulting temperature was lower due to the shorter combustion time. Fig. 4.b, shows the combustion temperature displayed in three dimensions (3D). It is shown that the combustion temperature of the three fuels used began to increase from $402.4^{\circ} \mathrm{C}$ to $815.4^{\circ} \mathrm{C}$ and decreased until the end of testing. Besides, the modification of a perforated plate with four windpipe steering's entering the combustion chamber showed better results.
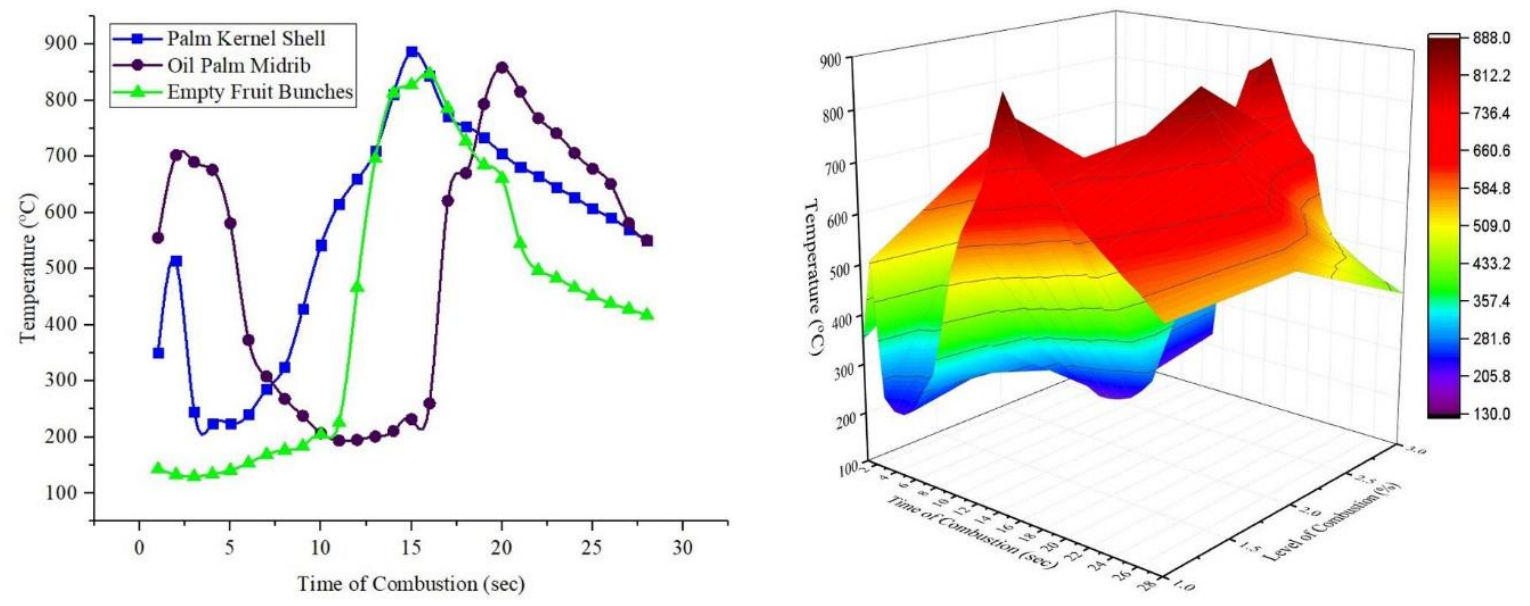

a. Combustion temperature at M2
b. 3D display on M2 metering

Fig. 5. Combustion Temperature Level of M2 at Different Time and Fuel

Temperature measurement results analyzed on M2 with 30 seconds of three fuel types show that EFB materials are more stable than PKS and OPM as shown in Fig. 5.a. At the beginning of combustion, OPM fuel showed a significant increase compared to EFB. However, by the time the 11-13 seconds decreased drastically and began to increase Back at 14 seconds. The maximum combustion temperature of OPM reaches $858^{\circ} \mathrm{C}$ which is recorded at 20 seconds and decreases until testing is complete.

Test results for PKS fuel analyzed on the M2 showed a slight instability at the start of testing up to 10 seconds. Furthermore, it continues to increase until the 15 th second which reaches $887^{\circ} \mathrm{C}$, and decreases until testing is complete. While EFB fuel indicates a more stable combustion temperature. However, the maximum combustion temperature produced is lower than that of PKS and OPM. The maximum temperature of EFB fuel test results reaches $847^{\circ} \mathrm{C}$ as shown in Fig. 5.a. The combustion fire state of the three types of biomass used is shown in Fig. 5.b. Where it can be explained that the equalization of fire in the combustion chamber is quite spread and stable. This is because the wind that enters from the blower through the steering plate of the hole is modified very sufficiently so that the fuel incorporated is burned thoroughly.

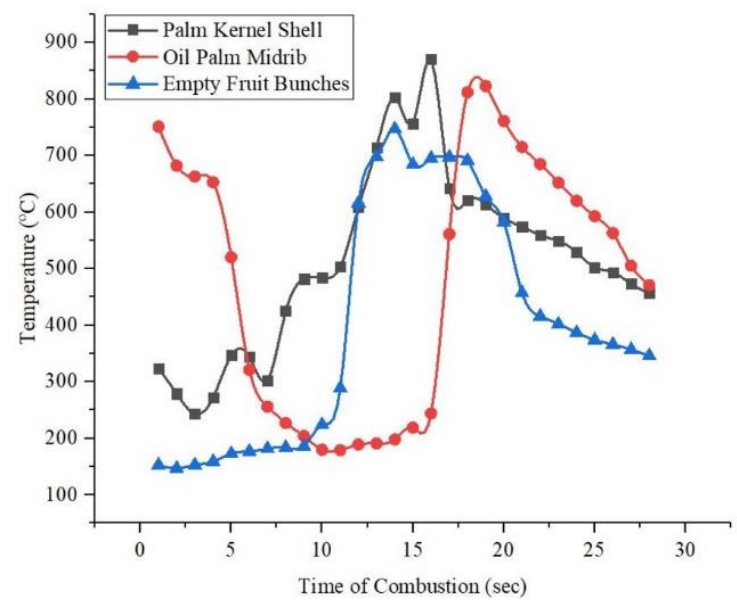

a. Combustion temperature on M3

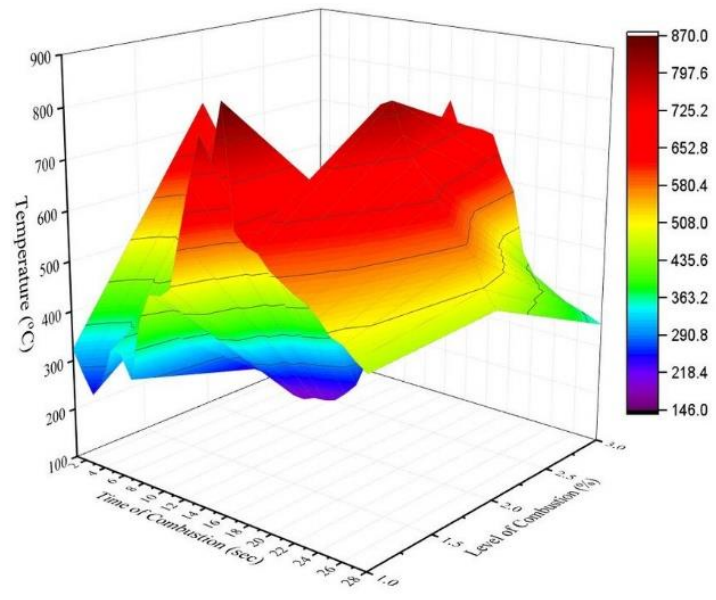

b. Temperature 3D display on M3

Fig. 6. Combustion Temperature Measurement of M3 at Different Time and Fuel

Furthermore, the analysis in this test was conducted at the M3 point which aims to determine the maximum temperature in the lower freeboard chamber after the combustion chamber. The results of the analysis conducted on the M3 that OPM fuel at the beginning of 
testing showed a higher temperature than reached $520^{\circ} \mathrm{C}$. This temperature height can be affected by the state of fire that suddenly jumps up, resulting in higher temperatures. This is evident clearly at 10 seconds decreases significantly and begins to increase again at 15 seconds. The maximum temperature of the analysis using OPM fuel was recorded at 19 seconds reaching $823^{\circ} \mathrm{C}$ as shown in Fig. 6.a. While the results of the analysis of the test using PKS fuel maximum combustion temperature obtained reached $870^{\circ} \mathrm{C}$ and showed more stable results than OPM. Meanwhile, the analysis of EFB fuel usage showed better stability both at the beginning and towards the end of the test. The maximum temperature of EFB fuel for point $\mathrm{M} 3$ reaches $747^{\circ} \mathrm{C}$ recorded at 14 seconds. Temperature stability analyzed at the M3 test point as shown in Fig. 6.b. Despite the increase in initial combustion for OPM fuels, overall, it showed fairly stable results. This can be seen in the rest of the final burning ash. Where all three types of fuel are used there is nothing left as shown in Fig. 7.

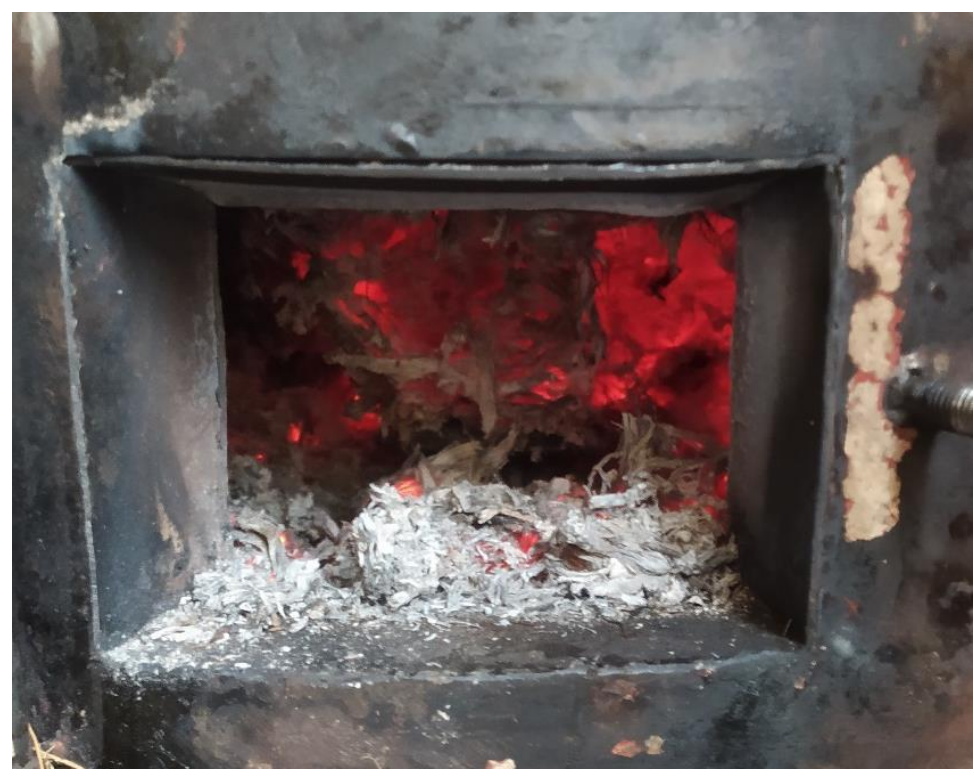

Fig. 7. Residual Ashes after Burning Process

Further analysis was conducted in this study at the M4 point with the same time and fuel from the previous analysis. Measurements on the M4 are performed to determine the maximum heat temperature level when reaching the boiler. Based on the results of the analysis showed that OPM fuel was slightly higher recorded at 19 seconds of $757^{\circ} \mathrm{C}$. While the maximum heat temperature of the PKS and EFB reached $729^{\circ} \mathrm{C}$ and $692^{\circ} \mathrm{C}$ respectively shown in Fig. 8.a. While the heat temperature phenomenon of the three types of fuel used shows better results as shown in Fig. 8.b. 


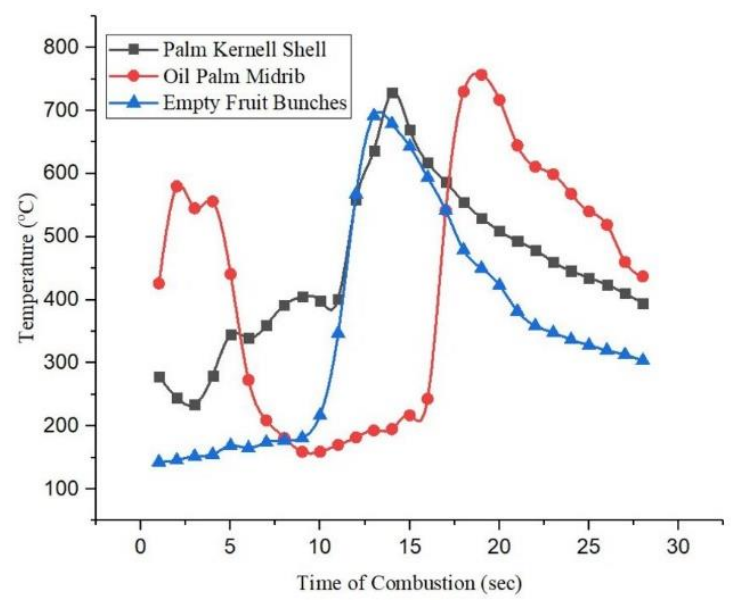

a. Combustion temperature on M4

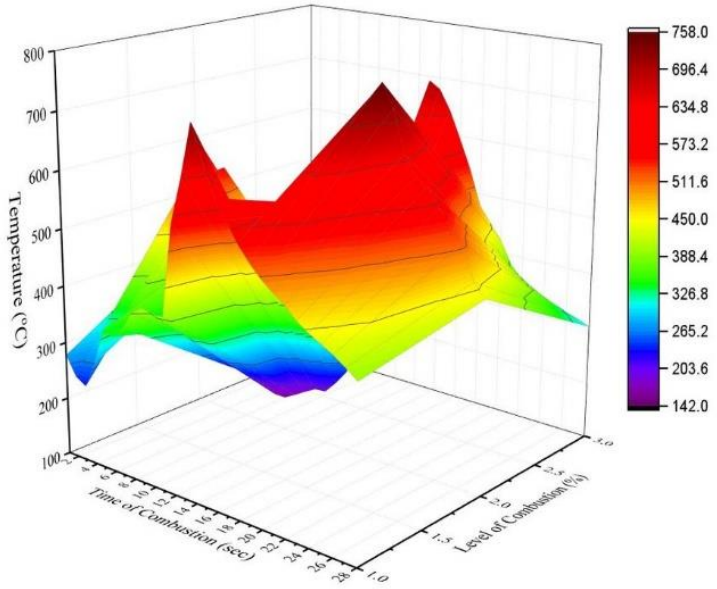

b. 3D temperature display on M4

Fig. 8. Temperature Measurement of M4 at Different Fuels

The latest analysis of the combustion chamber temperature on the outer wall aims to calculate the level of combustion efficiency. The phenomenon and temperature of the outer combustion chamber walls are necessary to predict the level of efficiency produced. The outer wall temperature of the PKS combustion indicates a stable temperature compared to OPM and EFB. At 20 seconds the temperature shows a drastic decrease in OPM fuel. This decrease is affected by malfunctioning dredging tools (errors) as shown in Fig. 9.a. This result is reinforced from the results of the 3D analysis in Fig. 9.b.

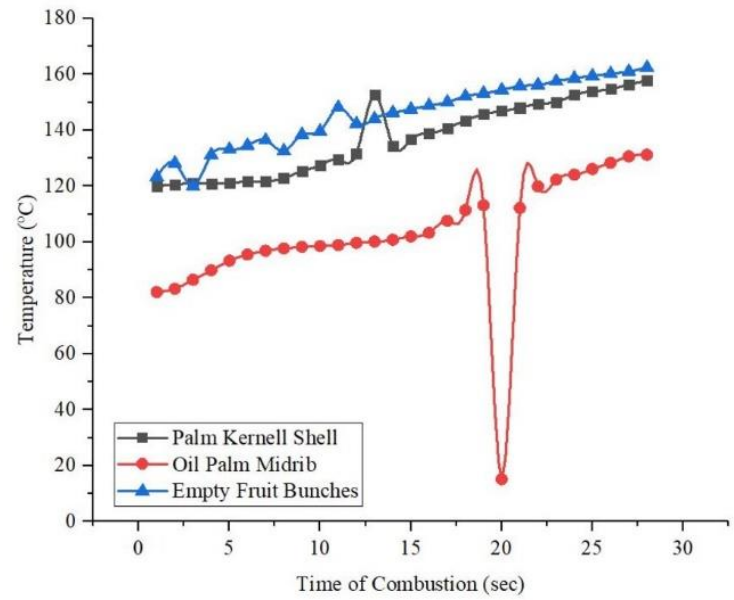

a. Combustion temperature on the outer wall

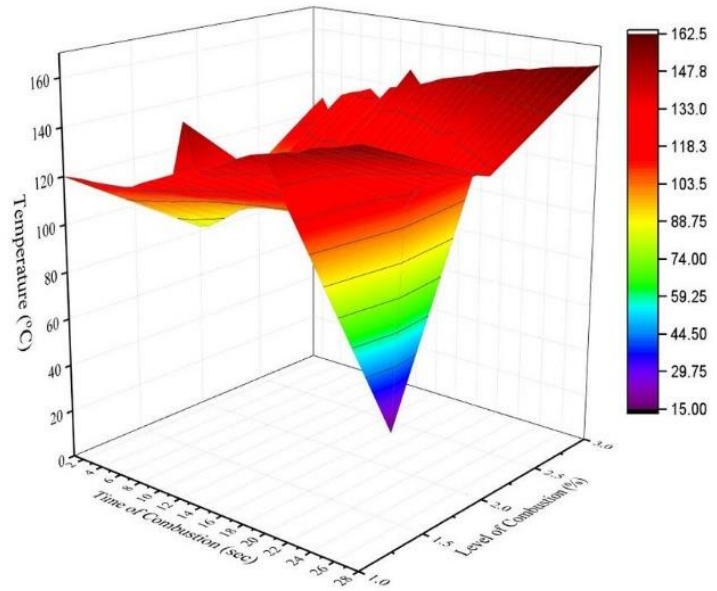

b. Temperature 3D display on the outer wall

Fig. 9. FBC Wall Temperature of Different Fuels 


\subsection{Combustion Efficiency}

The combustion process in the combustion chamber to produce heating, cooling and electrical energy need to be calculated efficiently so that the energy produced can be predicted. The efficiency of the furnace or better known as the FBC combustion chamber can be done by equation (2).

$$
\text { Eff }=\frac{\text { Pout }}{\text { Pin }} \times 100 \%
$$

Where

$$
\begin{array}{ll}
\text { Eff } & =\text { efficiency } \\
P_{\text {in }} & =\text { power input } \\
P_{\text {out }} & =\text { power output }
\end{array}
$$

The results of the calculation of furnace efficiency were obtained that OPM fuels showed better results compared to PKS and EFB fuels. The furnace efficiency levels recorded were recorded for OPM 11.23\%, PKS 10.78\%, and EFB 9.36\% respectively. The results of the search in various publications showed that investigations of the efficiency of fuel furnaces are still very rarely found. Studies comparing thermal efficiency between AFC and OFC in axialfueled heating furnaces have been studied [17]. Measurement of furnace efficiency tested with five different cases can increase efficiency by $50 \%$. However, previous tests have shown that in general efficiency measurements are not within the FBC space. Also, the fuel used in previous studies uses liquid fuel in general.

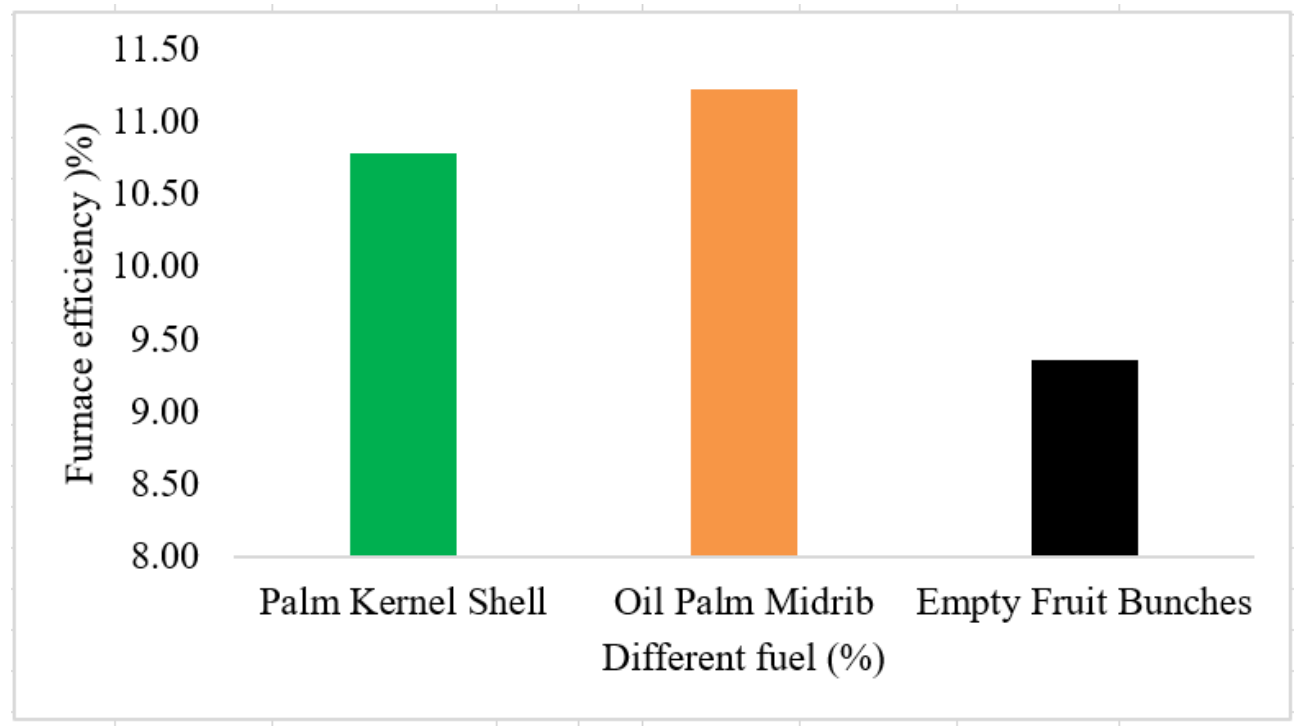

Fig. 10. Furnace Efficiency in the FBC for Different Fuel 


\subsection{Thermal Efficiency}

The calculation of thermal efficiency in a combustion test is a very important variable. It aims to know the efficient combustion resulting from the fuel used. Calculation of thermal efficiency can be done using equations (3) [18].

$$
\eta_{t h}=\frac{m a C p \Delta T}{m b L H V_{\text {fuel }}}
$$

Where:

$$
\begin{array}{ll}
m a & =\text { water }(\mathrm{kg}) \\
C p & =\text { heat capacity }\left(\mathrm{kJ} / \mathrm{kg}{ }^{\circ} \mathrm{C}\right) \\
\Delta T & =\text { end value }- \text { first value } \\
m b & =\text { total fuel } \\
L H V_{\text {fuel }} & =\text { lower heating value }
\end{array}
$$

Based on the results of the calculation calculations made that thermal efficiency with the use of OPM fuel reached $72.62 \%$. While the FBC chamber tested using PKS fuel can produce thermal efficiency of $70.04 \%$. EFB fuel combustion testing can deliver thermal efficiency of $52.43 \%$. The level of thermal efficiency in the FBC combustion chamber used in this study was lower than that of the [19]. Where the final thermal efficiency produced through the design of the solar receiver reaches $84.20 \%$. Meanwhile, different studies predicting the thermal efficiency of LPG energy-efficient burners (EB) using CFD data showed lower yields than thermal efficiency in the FBC space in this study. The results of the calculation of the experiments conducted from both burners were carried out at $9.02 \%$ and $7.87 \%$ respectively. While in different studies tested in combustion engines using mixed fuels between flaxseed oil and diesel showed lower thermal efficiency [20].

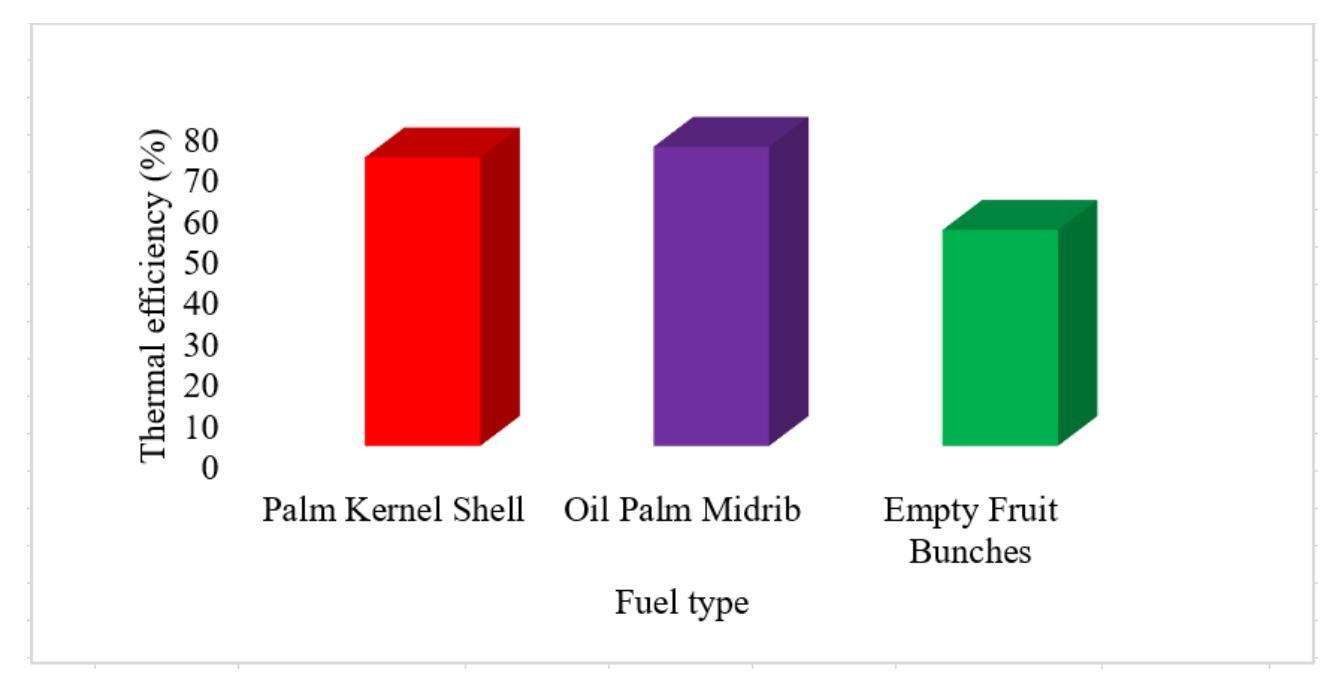

Fig. 11. Effect of thermal efficiency for different fuel 


\subsection{Measurement Heat Transfer Coefficient}

Calculation of heat transfer in combustion needs to be done so that the necessary energy needs can be known. Besides, the calculation of heat transfer also aims to find out how much efficiency of combustion furnaces produced in this study. The calculation of heat transfer in this test was done using Equation (4) [18].

$$
q=\frac{T 1-T 5}{\frac{1}{h o A o}+\frac{\ln \left(\frac{r O 1}{r i 1}\right)}{k 1}+\frac{\ln \left(\frac{r O 2}{r i 2}\right)}{k 2}+\frac{\ln \frac{r O 3}{r i 3}}{k 1}+\frac{1}{h i A i}}
$$

Where:

$$
\begin{array}{ll}
T 1 & =\text { Temperature Fluid } \\
T 5 & =\text { Temperature wall } \\
r o 1 & =\text { The outer radius of the cylinder } \\
r i 1 & =\text { Radius in cylinder } \\
r o 2 & =\text { The outer radius of insulation } \\
r i 2 & =\text { The outer radius in isolation } \\
r i 3 & =\text { Radius in cylinder } \\
k 1 & =\text { Thermal conductivity of the plate } \\
k 2 & =\text { Insulating conductivity } \\
h o & =\text { Convection heat transfer coefficient } \\
h i & =\text { The coefficient in the wall } \\
A o & =\text { Outer cross-sectional area } \\
A i & =\text { Inner cross-sectional area }
\end{array}
$$

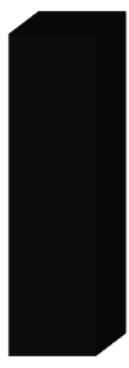

Palm Kernel Shell

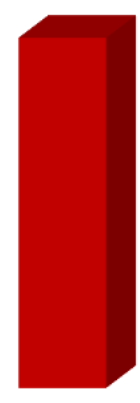

Oil Palm Midrib Different fuel

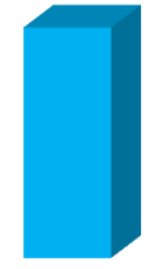

Empty Fruit Bunches

Fig. 12. Heat transfer coefficient for different fuel 
Based on the results of the calculations showed that the rate of heat transfer in combustion furnaces conducted with oil palm biomass fuel is higher than the results of experiments in the study [21]. The heat transfer rate of OPM fuel reached $7792.36 \mathrm{w} / \mathrm{m}$ at 21 minutes compared to the PKS shown in Figure 12. While the heat transfer rate for EFB fuels showed lower yields of $5127.83 \mathrm{w} / \mathrm{m}$ and PKS of $7167.38 \mathrm{w} / \mathrm{m}$. However, the overall fuel used in this study was higher than [22]. In the study they used component main heat transfer from fuel combustion is primary air as much as $33 \%$, charcoal does not burn as much as $25 \%$, pots $23 \%$, others by $14 \%$, and fuel space by $6 \%$. The resulting efficiency rate is $24 \%$ with a time of 17 minutes. While the experiments conducted in this study used palm oil biomass fuel with a test time of 28 minutes. Overall, the fuel used is not as important as shown in Fig. 7. The results of the study on the calculation of heat transfer rates conducted earlier are lower than the experiments in this study [23].

\section{Conclusion}

The tests conducted in the study aimed to analyze the temperature and efficiency of combustion using three different types of biomass fuels. Temperature measurements are allocated at five different points denoted by M1, M2, M3, M4, and M5. The fuel used is palm oil biomass solid waste such as PKS, OPM, and EFB. The measurement results in this study can be drawn some conclusions as follows:

1. Combustion temperatures on $\mathrm{M} 1$ and $\mathrm{M} 2$ reached $863^{\circ} \mathrm{C}$ and $887^{\circ} \mathrm{C}$ respectively from PKS fuel.

2. Overall, the phenomenon of combustion temperature obtained shows excellent and perfect results. This is as shown in Fig. 7.

3. Modification of the perforated plate by providing four air conditioners supplied from the blower into the combustion chamber is quite perfect.

4. Furnace efficiency levels using PKS, OPM, and EFB fuels were 10.78\%, 11.23\%, and $9.36 \%$, respectively.

5. The highest thermal efficiency in the FBC fuel chamber reaches $72.62 \%$ for OPM fuel. Meanwhile, thermal efficiency for PKS and EFB fuels was $70.03 \%$ and $52.43 \%$ respectively.

6. The highest heat transfer rate was obtained from OPM fuels reaching $7792.36 \mathrm{w} / \mathrm{m}$. While the heat transfer rates for PKS and EFB fuels were $7167.38 \mathrm{w} / \mathrm{m}$ and $5127.83 \mathrm{w} / \mathrm{m}$, respectively. 


\begin{tabular}{|llll|}
\hline Nomenclature & & \\
PKS & Palm kernel shell & $m a$ & water $(\mathrm{kg})$ \\
OPM & Oil Palm Midrib & $C p$ & heat capacity $\left(\mathrm{kJ} / \mathrm{kg}{ }^{\circ} \mathrm{C}\right)$ \\
EFB & Empty fruit bunches & $\Delta T$ & end value - first value \\
$T 1$ & Temperature Fluid & $m b$ & total fuel \\
$T 5$ & Temperature wall & $L H V_{\text {fuel }}$ & lower heating value \\
$r o 1$ & The outer radius of the cylinder & $E f f$ & efficiency \\
$r i 1$ & Radius in cylinder & $P_{\text {in }}$ & power input \\
$r o 2$ & The outer radius of insulation & $P_{\text {out }}$ & power output \\
$r i 2$ & The outer radius in isolation & $\mathrm{w} / \mathrm{m}$ & Watt/meter \\
$r i 3$ & Radius in cylinder & $\mathrm{M} 1$ & Measurement 1 \\
$k 1$ & Thermal conductivity of the plate & $\mathrm{M} 2$ & Measurement 2 \\
$k 2$ & Insulating conductivity & $\mathrm{M} 3$ & Measurement 3 \\
$h o$ & Convection heat transfer coefficient & $\mathrm{M} 4$ & Measurement 4 \\
$h i$ & The coefficient in the wall & $\mathrm{M} 5$ & Measurement 5 \\
$A o$ & Outer cross-sectional area & $A i$ & Inner cross-sectional area \\
\hline
\end{tabular}

\section{Acknowledgment}

This research is supported by the KEMENRISTEK DIKTI and Higher Education Syiah Kuala University, Research institutions, and community service with the contract number of (20/UN11.2/PP/PNBP/SP3/2019).

\section{References}

[1] Erdiwansyah, Mamat R, Sani MSM, Sudhakar K. Renewable energy in Southeast Asia:

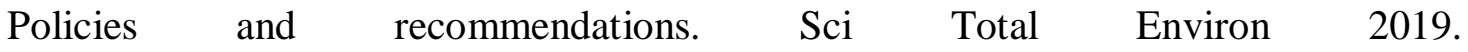
https://doi.org/https://doi.org/10.1016/j.scitotenv.2019.03.273.

[2] Erdiwansyah, Mahidin, Mamat R, Sani MSM, Khoerunnisa F, Kadarohman A. Target and demand for renewable energy across 10 ASEAN countries by 2040. Electr J 2019;32:106670. https://doi.org/10.1016/J.TEJ.2019.106670.

[3] Murphy CA, Schleifer A, Eurek K. A taxonomy of systems that combine utility-scale renewable energy and energy storage technologies. Renew Sustain Energy Rev 2021;139:110711. https://doi.org/https://doi.org/10.1016/j.rser.2021.110711.

[4] Shahidul MI, Malcolm ML, Begum S, Hashmi MSJ, Islam MS, Eugene JJ. Renewable Energy Production From Environmental Hazardous Palm Oil Mill Waste Materials: A Review. In: Hashmi S, Choudhury IABT-E of R and SM, editors., Oxford: Elsevier; 2020, p. 902-14. https://doi.org/https://doi.org/10.1016/B978-0-12-803581-8.11564-4.

[5] $\mathrm{Ng} \mathrm{KH}$, Yuan LS, Cheng CK, Chen K, Fang C. TiO2 and ZnO photocatalytic treatment of palm oil mill effluent (POME) and feasibility of renewable energy generation: A short review. J Clean Prod 2019;233:209-25. 
https://doi.org/https://doi.org/10.1016/j.jclepro.2019.06.044.

[6] Ahmad A, Buang A, Bhat AH. Renewable and sustainable bioenergy production from microalgal co-cultivation with palm oil mill effluent (POME): A review. Renew Sustain Energy Rev 2016;65:214-34. https://doi.org/https://doi.org/10.1016/j.rser.2016.06.084.

[7] Mahidin, Saifullah, Erdiwansyah, Hamdani, Hisbullah, Hayati AP, et al. Analysis of power from palm oil solid waste for biomass power plants: A case study in Aceh $\begin{array}{lll}\text { Province. } & \text { 2020:126714. }\end{array}$ https://doi.org/https://doi.org/10.1016/j.chemosphere.2020.126714.

[8] Tewarson A. Generation of heat and chemical compounds in fires. SFPE Handb Fire Prot Eng 2002:82-161.

[9] Ishikawa T, Kasumi K, Tanaka F, Moinuddin KAM. Combustion efficiency during fires in tunnels with natural ventilation by vitiated air including descending smoke. Fire Saf J 2020:103093.

[10] White JP, Link ED, Trouvé A, Sunderland PB, Marshall AW. A general calorimetry framework for measurement of combustion efficiency in a suppressed turbulent line fire. Fire Saf J 2017;92:164-76. https://doi.org/https://doi.org/10.1016/j.firesaf.2017.06.009.

[11] Qin L, Han J, Chen W, Yao X, Tadaaki S, Kim H. Enhanced combustion efficiency and reduced pollutant emission in a fluidized bed combustor by using porous alumina bed materials. Appl Therm Eng 2016;94:813-8. https://doi.org/https://doi.org/10.1016/j.applthermaleng.2015.10.153.

[12] Peng W, Liu Z, Motahari-Nezhad M, Banisaeed M, Shahraki S, Beheshti M. A detailed study of oxy-fuel combustion of biomass in a circulating fluidized bed (CFB) combustor: Evaluation of catalytic performance of metal nanoparticles (Al, Ni) for combustion efficiency improvement. Energy 2016;109:1139-47. https://doi.org/https://doi.org/10.1016/j.energy.2016.04.130.

[13] Permchart W, Kouprianov VI. Emission performance and combustion efficiency of a conical fluidized-bed combustor firing various biomass fuels. Bioresour Technol 2004;92:83-91. https://doi.org/https://doi.org/10.1016/j.biortech.2003.07.005.

[14] Wang D, Wang $H$, Xing J, Wang Y. Investigation of the thermal-hydraulic characteristics in the shell side of heat exchanger with quatrefoil perforated plate. Int $\mathbf{J}$ Therm Sci 2021;159:106580. https://doi.org/https://doi.org/10.1016/j.ijthermalsci.2020.106580.

[15] Mentzoni F, Kristiansen T. Two-dimensional experimental and numerical investigations of parallel perforated plates in oscillating and orbital flows. Appl Ocean Res 
2020;97:102042. https://doi.org/https://doi.org/10.1016/j.apor.2019.102042.

[16] Ninduangdee P, Kuprianov VI. Combustion of Oil Palm Shells in a Fluidized-bed Combustor Using Dolomite as the Bed Material to Prevent Bed Agglomeration. Energy Procedia 2014;52:399-409. https://doi.org/https://doi.org/10.1016/j.egypro.2014.07.092.

[17] Han SH, Lee YS, Cho JR, Lee KH. Efficiency analysis of air-fuel and oxy-fuel combustion in a reheating furnace. Int $\mathbf{J}$ Heat Mass Transf 2018;121:1364-70. https://doi.org/https://doi.org/10.1016/j.ijheatmasstransfer.2017.12.110.

[18] Holman JP. Perpindahan Kalor (terjemahan E. Jasfi). Jakarta Penerbit Erlangga(Buku Asli 1986) 1988.

[19] Xiao G, Zeng J, Nie J. A practical method to evaluate the thermal efficiency of solar molten salt receivers. Appl Therm Eng 2021;190:116787. https://doi.org/https://doi.org/10.1016/j.applthermaleng.2021.116787.

[20] Agrawal BN, Sinha S, Kuzmin A V, Pinchuk VA. Effect of vegetable oil share on combustion characteristics and thermal efficiency of diesel engine fueled with different blends. Therm Sci Eng Prog 2019;14:100404. https://doi.org/https://doi.org/10.1016/j.tsep.2019.100404.

[21] Yu Z, Tao L, Huang L, Wang D. Numerical investigation on cooling heat transfer and flow characteristic of supercritical $\mathrm{CO} 2$ in spirally fluted tubes. Int J Heat Mass Transf 2020;163:120399.

https://doi.org/https://doi.org/10.1016/j.ijheatmasstransfer.2020.120399.

[22] Gogoi B, Baruah DC. Steady state heat transfer modeling of solid fuel biomass stove: Part 1. Energy 2016;97:283-95. https://doi.org/https://doi.org/10.1016/j.energy.2015.12.130.

[23] Faisal M, Usman U. Analisa Perpindahan Panas Pada Tungku Rocket Tipe Silinder Berbahan Bakar Biomassa. Pros. SEMDI-UNAYA (Seminar Nas. Multi Disiplin Ilmu UNAYA), vol. 3, 2019, p. 393-401. 